\title{
KEBIJAKAN PENGELOLAAN PAJAK BUMI DAN BANGUNAN \\ PERDESAAN DAN PERKOTAAN DINAS PENDAPATAN, PENGELOLAAN KEUANGAN DAN ASET DAERAH KABUPATEN MUSI RAWAS
}

\author{
Anton Mardoni \\ Program Studi Ilmu Administrasi Negara FISIP Universitas Musi Rawas Jalan \\ Pembangunan Komplek Perkantoran Pemkab Musi Rawas Kelurahan \\ Air Kuti Kecamatan Lubuklinggau Timur I Kota Lubuklinggau \\ email: doniesip@yahoo.co.id
}

\begin{abstract}
Abstrak
Penelitian bertujuan mengetahui kebijakan pengelolaan Pajak Bumi dan Bangunan Perdesaan dan Perkotaan (PBB-P2). Metode penelitian deskriptif kualitatif, pengumpulan data dengan melaksanakan observasi, wawancara mendalam, dokumentasi, dan analisis data interaktif Miles dan Huberman. Peraturan daerah dan peraturan kepala daerah lokasi penelitian merupakan dasar hukum pengelolaan pajak tersebut. Hasil penelitian dilihat dari aspek pembentukan organisasi pengelolaan pajak berada di Bidang Dana Perimbangan dan Penerimaan Lainnya dan Unit Pelaksana Teknis. Aspek pengerahan sumber daya telah dibangunnya gedung khusus yang dilengkapi loket pembayaran pajak. Sedangkan sumber daya manusia yaitu pegawai telah mengikuti magang. Aspek penyiapan teknologi disesuaikan dengan volume pekerjaan dan jumlah wajib pajak. Aspek p enetapan prosedur berdasarkan hasil pengumpulan data sekunder bahwa belum terdapat standar operasional prosedur pemungutan pajak tersebut di atas. Adapun kendala yang dihadapi belum seimbangnya jumlah sumber daya manusia dibandingkan dengan jumlah desa dan kelurahan yang ada. Upaya yang dilakukan pemerintah desa dan kelurahan dengan melaksanakan sosialisasi persuasif kepada wajib pajak.
\end{abstract}

Kata kunci: kebijakan pengelolaan

\section{Abstarct}

This research aims to investigate the policy of land and building management in village and city. Descriptive qualitative was used in this research, data collected by observation, depth interview, documentation, and analyze of data interactive Miles and Huberman. Local regulation and regent/district head regulation are the basis of law for tax management. The result of the research are based on the aspect of fiscal balance transfers from the central goverment to regions, miscellaneous revenue, and technical unit. The aspect of infrastructure was built specific office by tax payment counter. Menawhile, the aspect of human resource apprentice staff. The aspect of technology was adjucted to job volume and a number of taxpayer. The aspect of procedure based on the secondary data collection stated that there was no procedure of operation standard. There is no balanced of a number of human resource and the number of village, and disctrict administrative as the case contraint. The effort conducted by village and district administrative government through persuasive socialization to taxpayer.

Keyword: managemen policy 


\section{LATAR BELAKANG}

Kebijakan pengelolaan pajak daerah agar pemerintah daerah mempunyai tambahan pendapatan asli daerah yang salah satunya bersumber dari PBB-P2. Dinas sebagai lokasi penelitian ini telah mengelola secara mandiri PBB-P2 mulai Januari 2014. Luas wilayah yang merupakan lokasi penelitian sebanyak 14 Kecamatan, 13 Kelurahan dan 180 Desa membuat pelayanan kepada wajib pajak belum oftimal. Pendataan ulang objek dan subjek pajak belum dilaksanakan, tetapi telah dibentuk struktur organisasi dan tata kerja khusus pengeloaan PBB-P2.

\subsection{Tujuan Penelitian}

Tujuan penelitian dirumuskan sebagai berikut :

1. Mengetahui gambaran kebijakan pengelolaan PBB-P2 di Kabupaten Musi Rawas.

2. Mengetahui kendala-kendala yang dihadapi dalam pengelolaan pajak tersebut.

\section{METODE}

Metode penelitian deskriptif kualitatif untuk menghasilkan gambaran penomena sosial yang diteliti, teknik pengumpulan data dilakukan dengan observasi, wawancara, dokumentasi dengan mempelajari dokumen-dokumen yang berhubungan dengan kebijakan pengelolaan pajak tersebut. Informasi yang berkaitan dengan kebijakan pengelolaan pajak dikumpulkan melalui wawancara dengan informan. Informan yang ditetapkan adalah pihak-pihak yang mengetahui dengan jelas pengelolaan pajak tersebut sesuai lokasi penelitian.

\section{HASI DAN PEMBAHASAN}

Peraturan Bupati Musi Rawas Nomor 15 tahun 2014 Tentang Pelaksanaan Peraturan Daerah Kabupaten Musi Rawas Nomor 8 Tahun 2013 Tentang Perubahan Atas Peraturan Daerah Kabupaten Musi Rawas Nomor 2 Tahun 2012 Tentang Pajak Bumi dan Bangunan Perdesaan dan Perkotaan, tata cata pengelolaan PBB-P2 di Kabupaten Musi Rawas. Kebijakan pengelolaan PBB-P2 yang pelaksanaan kegiatannya diselenggarakan oleh Bidang Dana Perimbangan dan Penerimaan Lainnya yang membawahi Seksi Bagi Hasil Pajak, Seksi Bagi Hasil Bukan Pajak, dan Seksi Penerimaan lainnya dibantu oleh tiga orang staf.

Dinas terkait telah menyelenggarkan dan mensosialisasi pajak tersebut dengan melaksanakan penyuluhan pajak daerah dan restibusi daerah pada tahun 2014 . Penyuluhan pajak di atas dilaksanakan di Kecamatan Purwodadi pada tanggal 23 Mei 2015 dan Kecamatan Sukakarya pada tanggal 24 Mei 2014 dengan perserta perangkat desa, tokoh masyarakat, dan wajib pajak. Penyuluhan pajak agar aparat desa dan wajib pajak dapat memahami peraturan yang mengatur pemungutan pajak.

\subsection{Organisasi}

Kebijakan pengelolaan PBBP2 dengan melaksanakan penataan struktur organisasi dengan menambah fungsi pengelolaan PBBP2 pada Bidang Dana Perimbangan dan Penerimaan Lainnya dan Bidang Pendapatan Asli daerah. Pemungutan pajak tersebut dilaksanakan oleh UPT Pemungutan Pendapatan 
Wilayah Kecamatan dan dibantu pejabat fungsional yang secara administrasi didukung Bagian Tata Usaha.

Kepala Dinas terkait "G.T" mengemukakan: "Penataan struktur organisasi dengan menambah fungsi pengelolaan PBB-P2 tetap di Bidang Dana Perimbangan dan Penerimaan Lainnya" (wawancara 9 Maret 2015). Sekretaris Dinas "Y.S" menjelaskan : "PBB-P2 dikelola bidang yang ada dengan menambah fungsi pelayanan, pendataan dan penilaian, penerimaan, manajemen IT, penagihan, dan pengawasan" (wawancara10 Maret 2015). Kepala Bidang Dana Perimbangan dan Penerimaan Lainnya "T.H" menjelaskan : "Bidang dana Perimbangan dan Penerimaan Lainnya bekerjasama dengan Bidang Pendapatan Hasil Daerah dalam pengelolaan pajak dimaksud" (wawancara13 Maret 2015). Peraturan Bupati Musi Rawas Nomor 11 Tahun 2008 Tentang Pembentukan Unit Pelaksana Teknis Pemungutan Pendapatan Daerah, pelaksanaan tugas secara operasional berkoordinasi dengan Camat dan Kepala Desa.

\subsection{Sumberdaya.}

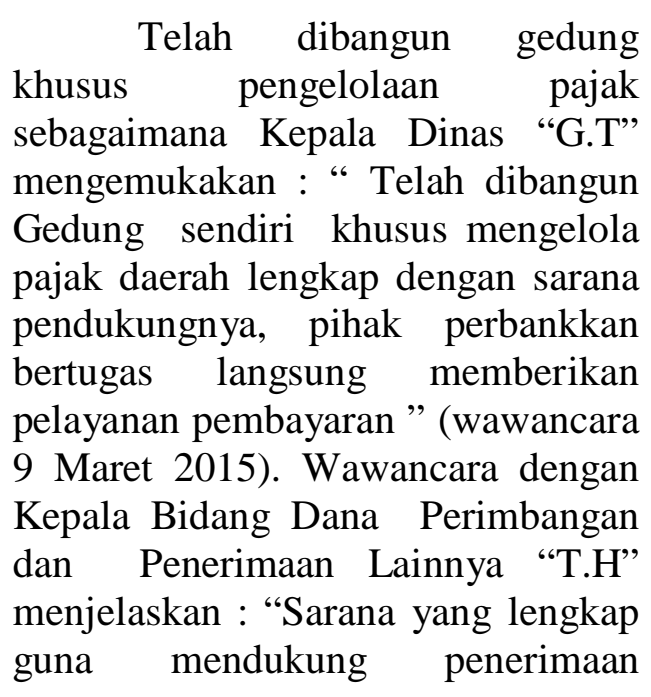

pajak sesuai struktur yang telah dibentuk" (wawancara 13 Maret 2015).

Telah dibangun gedung khusus pengelolaan PBB-P2 yang lengkap dengan sarana yang memadai, bekerjasama dengan Bank Sumsel dalam mengelola penerimaan pajak. Gedung khusus pengelolaan pajak dimaksud terdiri dari ruang tunggu dan loket pembayaran Bank Sumsel, ruang verifikasi, ruang pelayanan, ruang arsip, ruang pencetakan, toilet, dan musholah. Pegawai telah mengikuti magang dan workshop teknis penilaian PBBP2 yang diselenggarakan KPP Pratama dan Diklat keluar daerah sehingga pegawai pengetahuan tata cara mengelola PBB-P2.

\subsection{Teknologi}

Kepala Dinas tempat penelitian "G.T" menjelaskan : "Peralatan komputer didukung basis data PBB-P2 lengkap, mengadopsi aplikasi dari Ditjen Pajak" (wawancara 9 Maret 2015). Hasil wawancara dengan Kepala Bidang Dana Perimbangan dan Penerimaan Lainnya "T.H" mengemukakan bahwa : "Peralatan komputer lengkap dengan Basis Data PBBP2 dan didukung alat-alat yang telah disediakan seperti alat mesin cetak SPPT, lembaran Formulir dan Bukti Pembanyaran SPPT PBB-P2. Basis data SPPT diperoleh dari KPP Pratama Lubuklinggau sebanyak 14 Kecamatan, 185 desa dan 8 kelurahan dengan jumlah SPPT sebanyak 118.320 SPPT. SPPT terbesar berada di Kecamatan Megang Sakti sebanyak 23.882 SPPT yaitu 20\%, sedangkan SPPT terkecil berada di Kecamatan Tiang Pumpung Kepungut sebanyak 2.145 yaitu $2 \%$. 


\subsection{Prosedur}

Kepala Dinas "G.T" menjelaskan : "dikarenakan pengelolaan PBB-P2 merupakan kebijakan baru, jadi membutuhkan waktu untuk mempersiapkan SOP" (wawancara 9 Maret 2015). Didukung pendapat Sekretaris DPPKAD Kabupaten Musi Rawas "Y.S" : "Telah ditentukan pihak yang terkait dalam proses pemungutan $\mathrm{PBB}$-P2 sesuai tugas dan fungsi masing-masing pihak terkait" (wawancara 10 Maret 2015).

Standar operasional prosedur belum ada, sebagaimana Kepala Bidang Dana Perimbangan dan Penerimaan Lainnya "T.H" mengemukakan : "belum ada standar operasional prosedur pendataan dan penilaian, penetapan dan pelayanan, penerimaan dan manajemen IT, penagihan, pengawasan". Sesuai dengan Peraturan Bupati Nomor 15 tahun 2014 telah ditentukan formulir yang digunakan, dokumen yang dihasilkan, dan alur proses dari masing-masing proses bisnis pemungutan PBB -P2" (wawancara 13 Maret 2015).

Prosedur tentang pihak yang terkait beserta tugas dan fungsinya dalam proses pemungutan PBB -P2, formulir-formulir yang digunakan, dokumen yang dihasilkan, dan alur proses pemungutan $\mathrm{PBB} \quad-\mathrm{P} 2$ tertuang dalam Peraturan Bupati Musi Rawas Nomor 11 Tahun 2008 dan Peraturan Bupati Nomor 15 Tahun 2014.

\subsection{Kendala-kendala yang dihadapi}

Hasil wawancara dengan informan diketahui bahwa terdapat masih kurangnya pemahaman pegawai dalam menentuhkan penilaian NJOP PBB-P2 dan rendahnya kesadaran wajib pajak untuk membayar pajak. Sumber daya manusia yang ahli dalam penilaian NJOP masih kurang, wawancara penulis dengan Kepala Bidang Dana Perimbangan dan Penerimaan Lainnya "T.H" menjelaskan : "Secara umum tidak ada kendala, masih kurangnya SDM yang ahli dalam penilaian NJOP" (wawancara 13 Maret 2015).

\subsection{Cara yang dilakukan untuk meminimalisir kendala- kendala.}

Rendahnya kesadaran masyarakat wajib pajak untuk membayar pajak. PBB- P2 sebagai salah sumber pendapatan asli daerah, maka terus dilakukan berbagai upaya untuk meningkatkan realisasi penerimaan PBB-P2 dapat tercapai di tahun 2014. Belum seimbangnya jumlah pegawai yang ada di Bidang Dana Perimbangan dan Pendapatan Lainnya, Bidang Pendapatan Asli daerah, dan UPT dibandingkan dengan jumlah kecamatan, Desa atau Kelurahan yang ada. Pemerintah desa dan kelurahan telah melaksanakan sosialisasi pajak secara persuasif.

Adapun temuan beberapa aspek yang menujang tercapainya kebijakan pengelolaan PBB-P2, sebagai berikut :

1. Himbauan Persuasif

Camat memberikan himbauan kepada Kepala Desa dan Lurah untuk segera melunasi pembayaran pajak dan memberikan SPPT kepada wajib pajak.

2. Kesadaran

Masyarakat baru akan membayar pajak ketika sudah ditagih atau ketika kewajiban perpajakan 
tersebut dikaitkan dengan layanan pemerintahan.

\section{SIMPULAN}

Berdasarkan hasil penelitian dan pembahasan kebijakan pengelolaan PBB- P2, sebagai berikut :

1. Organisasi pengelolaan PBB-P2 berada pada Bidang Dana Perimbangan dan Penerimaan Lainnya menjalankan fungsi pelayanan, pendataan dan penilaian, penerimaan, manajemen IT, penagihan, dan pengawasan.

2. Sumber daya seperti gedung khusus pengelolaan PBB-P2 yang lengkap dengan sarana teknologi informasi dan loket menerima pembayaran pajak. Sumber daya manusia menyesuaikan yang telah ada selama ini.

3. Teknologi seperti peralatan komputer lengkap dengan aplikasi SISMIOP dapat mencetak lembaran SPPT-PBB, SPOP, SKP-Daerah, SSPD, STTS, dan Surat Ketetapan Pajak Daerah Lebih Bayar (SKPDLB).

4. Prosedur, belum terdapat standar operasional prosedur yang menjabarkan proses bisnis pemungutan PBB-P2.

\section{DAFTAR PUSTAKA}

Agustino,

$$
\mathrm{L} \text {. }
$$

Dasar-Dasar Kebijakan Publik, Alfabeta. Bandung. Bungin, B. 2011.Penelitian Kualitatif: Komunikasi, Ekonomi, Kebijakan Publik, dan Isu Sosial Lainnya, Fajar Interpratama Offset, Jakarta.

Creswell, John W. 2010. Edisi ke- 1.Research Design Pendekatan Kualitatif,
Kuantitatif, dan Mixed, Yogyakarta.

Harbani, P. 2012. Metode Penelitian Administrasi Publik, Alfabeta, $\mathrm{CV}$. Bandung.

Keputusan Menteri Keuangan Nomor 316/KMK.07/2010

Tentang Pembentukan Tim Persiapan Pengalihan PBB-P2 dan Bea Peralihan Hak atas Tanah dan Bangunan Menjadi Pajak Daerah.

Kementerian Keuangan Republik Indonesia.2011. Tinjauan Pelaksaan Pengalihan Bea Perolehan Hak atas Tanah dan Bangunan (BPHTB) menjadi Pajak Daerah, Direktorat Jenderal Perimbangan Keuangan, Jakarta.

Kementerian Keuangan Republik Indonesia.2014. Pedoman Umum Pengelolaan Pajak Bumi dan Bangunan Perdesaan dan Perkotaan, Direktorat

Jenderal Perimbangan Keuangan, Jakarta.

Moleong, Lexy J. 2013. Metodologi Penelitian Kualitatif Edisi Revisi, Remaja Rosdakarya, PT. Bandung.

Undang-Undang Republik Indonesia Nomor 28 Tahun 2009 Tentang Pajak Daerah dan Retribusi Daerah.

Purwanto, E.A dan Dya Ratih Sulistyastuti. 2012. Implementasi Kebijakan Publik, Konsep dan Aplikasinya di Indonesia, Gava Media, Yogyakarta.

Peraturan Menteri Dalam Negeri Nomor 56 Tahun 2010 Tentang Perubahan Atas Peraturan Menteri Dalam Negeri Nomor 57 Tahun2007 Tentang Petunjuk Teknis Penataan Organisasi Perangkat Daerah. Peraturan Bersama Menteri Keuangan 
Menteri Dalam Negeri

Nomor 213/PMK.07/2010 dan

Nomor 58 Tahun 2010 tentang

Tahapan Persiapan Pengalihan

Pajak Bumi dan Bangunan

Perdesaan dan Perkotaan sebagai

Pajak Daerah.

Peraturan Direktur Jenderal Pajak

Nomor PER-61/PJ/2010 tentang

Tata Cara Persiapan Pengalihan

PBB Perdesaan dan Perkotaan sebagai Pajak Daerah.

Peraturan Daerah Kabupaten Musi

Rawas Nomor 2 Tahun 2008

Tentang Susunan Organisasi dan

Tata Kerja Dinas Daerah

Kabupaten Musi Rawas.

Peraturan Daerah Kabupaten Musi

Rawas Nomor 8 Tahun 2013

Tentang Perubahan Atas

Peraturan Daerah Kabupaten

Musi Rawas Nomor 2 Tahun

2012 Tentang Pajak Bumi

Dan Bangunan Perdesaan dan

Perkotaan. Peraturan Bupati

Kabupaten Musi Rawas

Nomor 11 Tahun 2008 Tentang

Pembentukan Unit Pelaksanaan

Teknis Pemungutan Pendapatan

Daerah Pada Dinas Pendapatan,

Pengelolaan Keuangan dan

Aset Daerah Kabupaten Musi

Rawas .

Peraturan Bupati Nomor 40

Tahun 2008 Tentang

Penjabaran Tugas Pokok dan

Fungsi Dinas Pendapatan,

Pengelolaan Keuangan dan

Aset Daerah Kabupaten Musi

Rawas.

Sulistiyani, AT dkk.2011.

Memahami Good Governance

Dalam Perspektif Sumber Daya

Manusia,

Gava

Media.Yogyakarta.

Sedarmayanti, 2012.Good

Governance dan Good
Corporate Governance, Mandar Maju. Bandung.

Suharto, E. 2012.Analisis

Kebijakan Publik, Panduan

Praktis Mengkaji Masalah dan

Kebijakan Sosial, Alfabeta,

CV. Bandung.

Siahaan, MP. 2013. Pajak Daerah dan Retribusi

Daerah.Rajagrafindo Persada, PT. Jakarta.

Sugiono, 2013.Metode Penelitian Kuantitatif, Kualitatif dan $R \& D$, Alfabeta, CV. Bandung.

Sugiono, 2013. Memahami Penelitian Kualilatif, Alfabeta, CV. Bandung. Saidi, M.D. 2011.Pembaharuan Hukum Pajak, Raja Grafindo Persada, PT. Jakarta.

TMbooks. 2013. Perpajakan, Esensi dan Aplikasinya.Andi Offset, CV. Yogyakarta.

Winarno, B, 2012. Kebijkan Pulik, Teori, Proses dan Studi Kasus, Buku Seru, PT. Jakarta. 